\title{
Geospatial Analysis of Vehicular Emissions in some Parts of Benin City, Nigeria
}

\author{
IYEKE, SD; *ILABOYA, IR; ABULU, EI \\ Department of Civil Engineering, Faculty of Engineering, University of Benin, P.M.B 1154, Benin City, Edo State, Nigeria \\ *Corresponding Author Email: rudolph.ilaboya@uniben.edu
}

\begin{abstract}
Decline in air quality over the years has been linked to the growing rate of urbanization and the increase in the number of vehicles plying the roads. The focus of this study is to monitor the incidence of vehicular emissions in some parts of Benin City and employ geostatistical techniques such as kriging interpolation to study the spatial distribution of some selected pollutants around the study area. Seven (7) georeferenced points, namely; University of Benin Main Gate, Ekosodin junction, Agen Junction, Super D junction, Nitel junction, Okhunmwun junction and Oluku Market junction were used for data collection. Pollutant from vehicular emission, namely; dinitrogen oxide $\left(\mathrm{NO}_{2}\right)$, carbon monoxide $(\mathrm{CO})$ including the total radiation were monitored in the morning and evening for a period of 35 days (7th July to 12th August 2020) with the aid of portable toxic gas monitors and radiation alert meters. Other parameters of interest which were also measured include; maximum temperature and wind speed using infra-red thermometers and portable anemometer. To ascertain the quality of the data, selected preliminary analysis, namely; test of normality, test of homogeneity, outlier detection and reliability test were done. Results of the study revealed a growing concentration of $\mathrm{CO}$ and $\mathrm{NO}_{2}$ around Ugbowo maingate and Okhunmwun community especially during the peak hours.
\end{abstract}

\section{DOI: https://dx.doi.org/10.4314/jasem.v24i12.10}

Copyright: Copyright $($ C 2020 Iyeke et al. This is an open access article distributed under the Creative Commons Attribution License (CCL), which permits unrestricted use, distribution, and reproduction in any medium, provided the original work is properly cited.

Dates: Received: 19 October 2020; Revised: 29 November 2020; Accepted: 11 December 2020

Keywords: Geospatial Analysis, Vehicular Emission, Air Pollution, Prediction Maps

Transportation is a major source of air pollution in many countries due to the high number of vehicles that are available on the roads today, and this number is continuously rising with population growth and purchasing power. In general, the effects on people are most intense in large urban centers with significant emission sources, unfavourable dispersion characteristics, and high population densities. (Adeyanju and Manohar, 2017). The large majority of today's cars and trucks are powered by using internal combustion engines that burn gasoline or other petroleum products (Huboyo et al, 2017). This is a process that yields harmful greenhouse gases that have adverse effects on the environment. Examples of such pollutants include; carbon monoxide which is emitted from vehicles when the carbon in fuel doesn't burn completely. On the other hand, hydrocarbon is a toxic compound of hydrogen and carbon which is emitted from the exhaust. Also, when fuel burns, nitrogen and oxygen react with each other and form nitrogen oxides $\left(\mathrm{NO}_{\mathrm{x}}\right)$. This oxide, together with particulate matters which are small particles of foreign substances in the air contributes to atmospheric haze and can cause damage to the lungs. Their behaviour is also similar to that of ammonia, lead and Sulphur dioxide (Adeyanju and Manohar, 2017). Tetraethyl lead and other types of lead which are added to gasoline in motor vehicles to improve the antiknock characteristics of the fuel in spark-ignition engines are the main source of lead in ambient air. About 70 to 75 percent of this lead is transformed into inorganic lead in vehicles' engines upon combustion and emitted to the atmosphere through the exhaust pipe along with 1 percent of the organic lead that passes through the engine unchanged (Bekir and Surhid, 1997). For a given fuel quality, concentrations of many of these pollutants are influenced by such factors as the air-fuel ratio in the cylinder at the time of combustion, ignition timing, combustion chamber geometry, engine parameters (for example, speed, load, and engine temperature), and use of emission control devices. (Chunshan et al, 2018, (Afroz et al., 2003). According to the World Health Organization air pollutants emitted from cars are believed to increase the risk of stroke, lung cancer, chronic and acute respiratory diseases such as asthma, heart disease, birth defects and eye irritation. Pregnant women who are exposed to polluted air are likely to experience pregnancy and birth related-issues including preterm births. Emerging evidence also suggests ambient air pollution may result to diabetes and neurological development in children. Some air pollutants and particulate matter from cars can be deposited on soil and surface waters where they enter the food chain; these substances can affect the 
reproductive, respiratory, immune and neurological systems of animals and even humans (Jiang and $\mathrm{Li}$, 2017). The core objective of this study is to apply basic statistical techniques for the spatial analysis of gaseous pollutants from vehicular emission in some parts of Benin City Metropolis.

Description of study area: The study area is limited to some parts of Benin City particularly Ugbowo and environs where serious traffic jam is experienced on daily bases. Benin City serves as the principal administrative and socio-economic center for both Oredo Local Government Area and Edo State in Nigeria. Benin City is a humid tropical urban settlement which comprises three Local Government Areas namely Egor, Ikpoba Okha and Oredo. It is located within latitudes $6^{0} 20^{\circ} \mathrm{N}$ and $6^{0} 58^{\circ} \mathrm{N}$ and longitudes $5^{0} 35^{\prime} \mathrm{E}$ and $5^{0} 41^{\prime} \mathrm{E}$. It broadly occupies an area of approximately $112.552 \mathrm{sq} \mathrm{km}$. This extensive coverage suggests spatial variability of weather and climatic elements. Benin City lies visibly in the southern most corner of a dissected margin: a prominent topographical unit which lies north of the Niger Delta, west of the lower Niger Valley, and south of the Western Plain (Okhakhu, 2010). The specific locations employed for data collection are presented in Figure 1

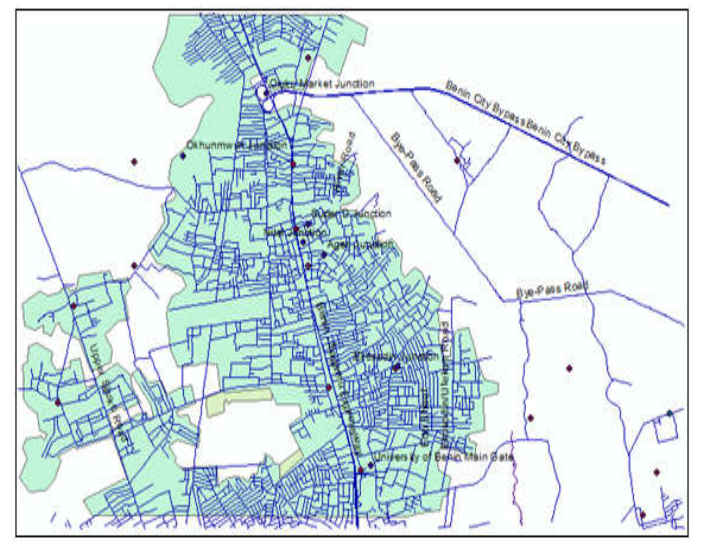

Fig 1: Map of study area

Table 1: Descriptive statistics of air quality data

\begin{tabular}{lllll}
\hline Parameters & Session & Mean & Standard Deviation & N \\
\hline \multirow{3}{*}{ Temperature } & Morning Session & 30.549 & 1.37160 & 245 \\
& Evening Session & 28.879 & 1.17880 & 245 \\
& Total & 29.714 & 1.52680 & 490 \\
Nitrogen Dioxide & Morning Session & 0.0181 & 0.01119 & 245 \\
& Evening Session & 0.0230 & 0.01282 & 245 \\
& Total & 0.0206 & 0.01226 & 490 \\
Carbon Monoxide & Morning Session & 0.5428 & 0.36396 & 245 \\
& Evening Session & 0.6169 & 0.32395 & 245 \\
& Total & 0.5799 & 0.34618 & 490 \\
Total Radiation & Morning Session & 0.2470 & 0.12850 & 245 \\
& Evening Session & 0.2810 & 0.12980 & 245 \\
& Total & 0.2540 & 0.13020 & 490 \\
\hline
\end{tabular}

IYEKE, SD; ILABOYA, IR; ABULU, EI
Data collection/Preliminary Analysis: Seven (7) georeferenced points, namely; University of Benin Main Gate, Ekosodin junction, Agen Junction, Super D junction, Nitel junction, Okhunmwun junction and Oluku Market junction were used for data collection. Pollutant from vehicular emission, namely; dinitrogen oxide $\left(\mathrm{NO}_{2}\right)$, carbon monoxide $(\mathrm{CO})$ including the total radiation were monitored in the morning and evening for a period of 35 days (7th July to 12th August 2020) with the aid of portable toxic gas monitors and radiation alert meters. Other parameters of interest which were also measured include; maximum temperature and wind speed using infra-red thermometers and portable anemometer. To ascertain the quality of the data, selected preliminary analysis using different statistical techniques, namely outlier detection using seasonal box plot method as proposed by Levi et al., (2009), test of homogeneity of data using the residual mass curve as proposed by Raes et al., (2006), test of normality using Jarque-Bera method and test of reliability using one-way analysis of variance were done.

Geospatial Analysis: For the spatial distribution of the pollutants, geospatial analysis using Kriging interpolation method was employed (Adeyanju and Manohar, 2017).

\section{RESULTS AND DISCUSSION}

Result of table 1 shows a high concentration of carbon monoxide and total radiation at peak hour of the day. At this time market women, business men/women including street traders and hawkers are in a rush to get home as such, the traffic situation at this point are usually very high. It is expected that the concentration may be higher than what is experienced presently when society recovers from the current pandemic occasioned by the corona virus. Result of normality test based on Jarque-Bera test statistics presented in Figure 2. Descriptive statistics of air quality data employed for the study is presented in Table 1 
The calculated Jarque-Bera test value was observed to be 49.54435 . Since the Jarque-Bera test value is greater than 10 with a (p-value) that is less than the $5 \%$ significant value, the null hypothesis of normality was rejected and it was concluded that the measured $\mathrm{CO}$ records did not follow a normal distribution. This is expected owing to the influence of temperature and wind speed on the dispersion of gaseous air pollutants. The same approach was applied to other pollutants and the results showed a non-normally distributed trend. On whether the data employed for the analysis is devoid of outlier, the seasonal box plot presented in Figure 3 was employed.

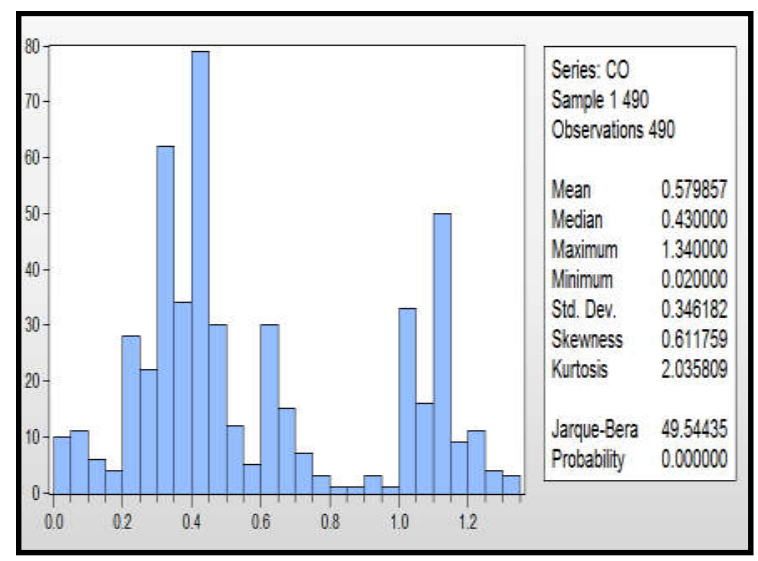

Fig 2: Normality test result of $\mathrm{CO}$ records around the study area

The presence of outlier is normally indicated with a square box or circle containing a number inside it. Since this was not noticeable in Figure 3, it was concluded that the measured $\mathrm{CO}$ data were devoid of possible outlier. The same approach was applied to other pollutants and the results showed that all the variables (air quality data) are devoid of outliers. To ascertain the reliability of the data, two-way mixed model having a confidence interval of $95 \%$ (p-value $=$ 0.05 ) and initial test value of 0 was employed. The null hypothesis of reliability was formulated as follows: $\mathrm{H}_{0}$ : Data are reliable and $\mathrm{H}_{1}$ : Data are not reliable.

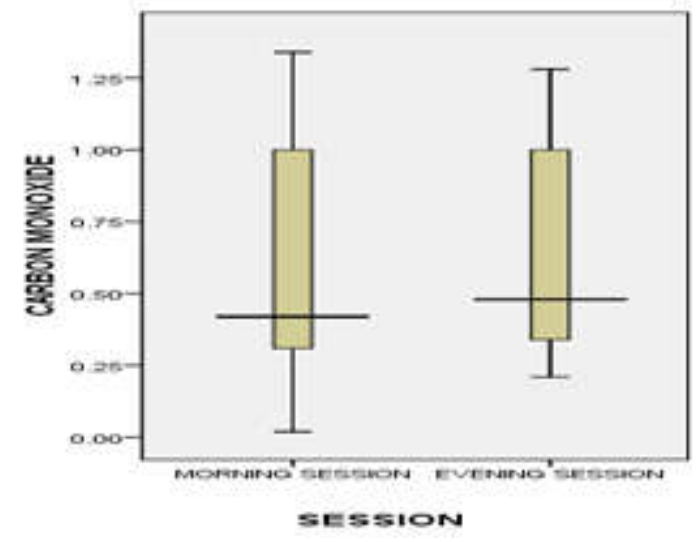

Fig 3: Seasonal box plot for assessing the presence of outliers in CO data

Using the Fisher's probability test (F-test), the analysis was conducted and the one-way analysis of variance (ANOVA) table was generated and presented in Table 2. At $0.05 \mathrm{df}$, with a computed p-value of 0.000 as observed in Table 2, the null hypothesis was accepted and it was concluded that the data are good and cam be employed for further analysis. To study the spatial distribution of the measured air pollutants around the study area, four semivariogram models, namely; stable, circular, spherical and exponential were fitted for geostatistical analysis in order to select the best fitted model. Using the different model, parameters of the semivariogram were generated. The semivariogram parameters for carbon monoxide are presented in Table 3 .

\begin{tabular}{|c|c|c|c|c|c|c|}
\hline & & Sum of Square & df & Mean Square & $\mathbf{F}$ & Sig. \\
\hline \multicolumn{2}{|l|}{ Between People } & 282.352 & 489 & 0.577 & $1.683 \mathrm{E} 5$ & .000 \\
\hline \multirow{3}{*}{ Within People; } & Between items & 318289.685 & 3 & 106096.562 & & \\
\hline & Residual & 924.584 & 1467 & 0.630 & & \\
\hline & Total & 319214.269 & 1470 & 217.153 & & \\
\hline $\begin{array}{l}\text { Total } \\
\text { Grand Mean = }\end{array}$ & .6446 & 319496.622 & 1959 & 163.092 & & \\
\hline
\end{tabular}

\begin{tabular}{lllll}
\multicolumn{6}{c}{ Table 3: Semivariogram parameters for CO } \\
\hline S/N & Model Type & Nugget & Major Range & Partial Sill \\
\hline 1. & Stable & 0.00671 & 0.1132078 & 0.118421 \\
2. & Circular & 17.9945 & 1.45302 & 42.9425 \\
3. & Spherical & 11.9523 & 1.45302 & 39.4403 \\
4. & Exponential & 12.8804 & 1.45302 & 41.0933 \\
\hline
\end{tabular}

Table 3 show the result of semivariogram parameters for $\mathrm{CO}$ and the corresponding values of nugget (the variability in the field data that cannot be explained by distance between the observations), major range (the distance at which two observations are unrelated/independent) and sill (the semi-variance at which the leveling takes place). The difference between the sill and the nugget is called partial sill. To select the model that best fit the measured data and which can be employed to generate the final prediction 
map, selected goodness of fit statistics, namely; Root mean square error (RMSE), Mean square error (MSE), Root mean square standardized error (RMSSE) and Average standard error (ASE) generated from the cross-validation step were employed. Estimated goodness of fit statistics corresponding to the different models is presented in Table 4. Based on the estimated root mean square error (RMSE) the best model for each of the four critical parameters was selected and presented in Table 5

Table 4: Calculated cross validation statistics for $\mathrm{CO}$

\begin{tabular}{llllll}
\hline S/N & Model Type & RMSE & MSE & RMSSE & ASE \\
\hline 1. & Stable & 0.083687 & -0.018190 & 0.891704 & 0.098274 \\
2. & Circular & 4.44074 & 0.064409 & 1.044678 & 2.226703 \\
3. & Spherical & 1.09452 & 0.057394 & 0.999871 & 4.004561 \\
4. & Exponential & 3.87452 & 0.237605 & 0.988091 & 4.220914 \\
\hline
\end{tabular}

Table 5: Summary table for estimating spatial dependence

\begin{tabular}{llllll}
\hline S/N & Parameter & Best Model & Nugget & Major Range & Partial Sill \\
\hline 1. & $\mathrm{NO}_{2}$ & Stable & 0.000067 & 0.1132078 & 0.000011 \\
2. & $\mathrm{CO}$ & Stable & 0.00671 & 0.1132078 & 0.118421 \\
3. & Radiation & Stable & 0.00011 & 0.0560795 & 0.0042554 \\
\hline
\end{tabular}

Table 6: Estimated spatial dependence of air quality parameters

\begin{tabular}{lllllll}
\hline Parameter & Best Model & $\begin{array}{l}\text { Nugget } \\
\left(\mathbf{C}_{\mathbf{n}}\right)\end{array}$ & Partial Sill & $\begin{array}{l}\text { Sill } \\
(\mathbf{C})\end{array}$ & {$\left[\mathbf{C}_{\mathbf{n}} / \mathbf{C}\right]$} & $\begin{array}{l}\text { Degree of Spatial } \\
\text { Dependency }\end{array}$ \\
\hline $\mathrm{NO}_{2}$ & Stable & 0.000067 & 0.000011 & 0.000078 & 0.859 & Strong \\
$\mathrm{CO}$ & Stable & 0.00671 & 0.118421 & 0.125131 & 0.054 & Strong \\
Radiation & Stable & 0.00011 & 0.0042554 & 0.0043654 & 0.0252 & Strong \\
\hline
\end{tabular}

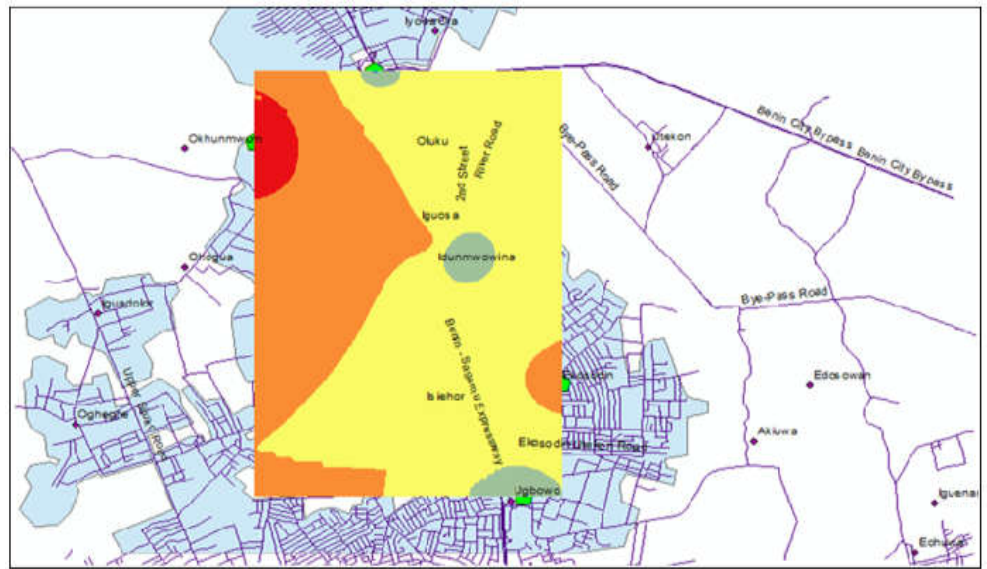

Fig 4: Final prediction map for the spatial distribution of CO (Evening Session)

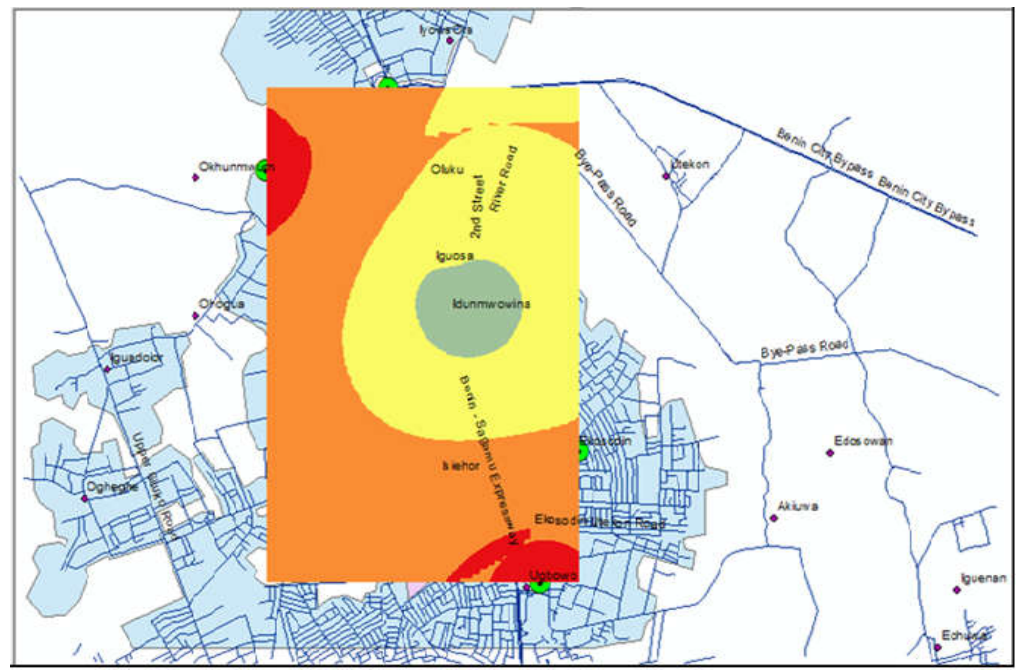

Fig 5: Final prediction map for the spatial distribution of $\mathrm{NO}_{2}$ (Evening Session)

IYEKE, SD; ILABOYA, IR; ABULU, EI 
The sill (c) is the summation of nugget and partial sill while the ratio of Nugget $\left(C_{n}\right)$ to Sill $(C)$ was employed to measure the degree of spatial structure (dependence). If the ratio is less than $25 \%$, the variable has strong partial dependence; between $25 \%$ and $75 \%$, the variable has moderate spatial dependence, and greater than $75 \%$, the variable shows only weak spatial dependence. The computed spatial dependence for the selected gaseous pollutants using the best fit model is presented in Table 6 . Result of Table 6 revealed that the gaseous parameters showed relatively strong degree of spatial dependency which made it possible to generate the spatial distribution map for the selected variables. Finally, the prediction map which can be employed to predict the concentration of vehicular emission around the study area was generated and presented in Figures 4 and 5 representing $\mathrm{CO}$ and $\mathrm{NO}_{2}$ concentration for evening session.

Areas with red colour codes represent higher values of CO. From the result of Figure 4, it was observed that high concentration of $\mathrm{CO}$ is present around Okhunmwun community and environs especially during the peak hous of evening when the traffic load is high. For $\mathrm{NO}_{2}$, it was oberseved from the results of Figure 5 that high concentration of $\mathrm{NO}_{2}$ are present around Ugbowo maingate and Okhunmwun community.

Conclusion: In this study, modelling, analysis and prediction of ground level concentrations of gaseous pollutants from vehicular emission in some selected locations around Benin-Logos road was done. To certify the adequacy of the field data, reliability analysis using one-way analysis of variance was employed to validate the data and the result revealed that the data were adequate for use. Results obtained show some level of environmental pollution in some parts of the City occasioned by vehicular emissions.

\section{REFERENCES}

Adeyanju, AA; Manohar, K (2017). Effects of Vehicular Emission on Environmental pollution in Lagos. Sci. Afr. J. Sci. Res. Essay 5 (4): 34-51

Afroz, R; Hassan, MN; Ibrahim, NA (2003). Review of air pollution and health impacts in Malaysia. Environ. Res. 92: 71-77
Akpan, UG; Ndoke, PN (1999). Contribution of vehicular traffic emission to $\mathrm{CO}_{2}$ emission in Kaduna and Abuja. Federal University of Technology, Minna Nigeria. Unpublished dissertation, 067-072

Bekir, O; Surhid, PG (1997). Vehicular Air Pollution (Experiences from seven Latin American urban centers). The World Bank Latin American and the Caribbean Region Technical Department Washington, D.C, 67; a review

Chunshan, Z; Shijie, L; Shaojian, W (2018). Examines the impacts of urban form on air pollution in developing countries: A case study of China's megacities. Int. J. Environ. Res. Pub. Health. 15 (1565): $1-18$

Huboyo, HS; Handayani, W; Samadikun, BP (2017). Potential air pollutant emission from private vehicles based on vehicle route. IOP conference series: Earth. Environ. Sci. 70 (1): 1-8

Jiang, XT; Li, R (2017). Decoupling and decomposition analysis of carbon emissions from electric output in the United States. Sustainability, 9 (6): $1-13$

Levi, DB; Julie, EK; Olsen, JR; Pulwarty, RS; Raff, DA; Turnipseed, DP; Webb, RS; Kathleen DW (2009). Climate Change and Water Resources Management: A Fed. Persp, 1331: 1 - 72

Okhakhu, PA (2010). Environmental and Human Challenges in the Niger-Delta Region of Nigeria. J. Environ. Earth Sci. 4(23): 112 - 134

Raes, D; Willens, P; Gbaguidi, A (2006). Rainbow A software package for analyzing data and testing the homogeneity of historical data sets, user manual, 1: 1-15 